\title{
Unlocking the chemistry of bile acids for cancer therapeutics
}

\author{
Avinash Bajaj \\ From International Conference on Human Genetics and 39th Annual Meeting of the Indian Society of \\ Human Genetics (ISHG) \\ Ahmadabad, India. 23-25 January 2013
}

Breast cancer is the second leading cause of cancer deaths today after lung cancer and is the most common cancer among women. The primary drug tamoxifen is used treat breast cancer has several problems including poor oral bioavailability. Bile acids/salts are known to be components of endogenous molecular pool that solubilizes, absorbs dietary fat/lipid molecules in the form of micelles. Bile acids are interesting chemical scaffold for drug conjugation due to presence of different number of free hydroxyl groups and a free carboxylic acid. We have been exploring bile acids as drug carriers for cancer therapy. We used three bile acids: lithocholic acid (LCA), deoxycholic acid (DCA) and cholic acid (CA) to engineer bile acid tamoxifen conjugates with free amine and acid functionalities. In this talk, I would present the interactions of these new drug carriers and their therapeutic potential for breast cancer therapy.

Published: 21 January 2014

Submit your next manuscript to BioMed Central and take full advantage of:

- Convenient online submission

- Thorough peer review

- No space constraints or color figure charges

- Immediate publication on acceptance

- Inclusion in PubMed, CAS, Scopus and Google Scholar

- Research which is freely available for redistribution

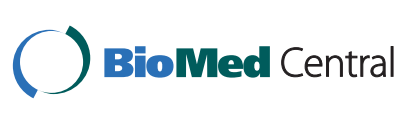

